\title{
Cadmium Compound
}

National Cancer Institute

\section{Source}

National Cancer Institute. Cadmium Compound. NCI Thesaurus. Code C44349.

An inorganic substance that contains the metallic element cadmium usually in its positive2 valence state and forms toxic fumes of cadmium oxide when heated. Cadmium compounds are used in industry in electroplating and coating, in pigments, in batteries, in alloys, and as stabilizers. Exposure to these substances affects the lungs and kidneys and is associated with an increased risk of developing lung cancer. ( $\mathrm{NCl05)}$ 